\title{
Herpes simplex virus infects most cell types in vitro: clues to its success
}

Ghadah A Karasneh ${ }^{1,2}$ and Deepak Shukla ${ }^{1,2^{*}}$

\begin{abstract}
Herpes simplex virus (HSV) type-1 and type-2 have evolved numerous strategies to infect a wide range of hosts and cell types. The result is a very successful prevalence of the virus in the human population infecting $40-80 \%$ of people worldwide. HSV entry into host cell is a multistep process that involves the interaction of the viral glycoproteins with various cell surface receptors. Based on the cell type, HSV enter into host cell using different modes of entry. The combination of various receptors and entry modes has resulted in a virus that is capable of infecting virtually all cell types. Identifying the common rate limiting steps of the infection may help the development of antiviral agents that are capable of preventing the virus entry into host cell. In this review we describe the major features of HSV entry that have contributed to the wide susceptibility of cells to HSV infection.
\end{abstract}

Keywords: Herpes simplex virus (HSV) type-1 and type-2, HSV entry, Receptors

\section{Introduction}

Herpes simplex viruses (HSV) are part of the alphaherpesvirus subfamily of herpesviruses. There are two types of HSV: type-1 (HSV-1) and type-2 (HSV-2). These viruses are neurotropic capable of infecting the nervous system and causing neurological diseases. Moreover, HSV results in a lifelong infection by establishing latency in the host sensory neurons and replicating in epithelial cells during primary infection and reactivation [1]. The virus is spread and transmitted among humans through physical contact and commonly causes localized mucocutaneous lesions [2]. Oral and ocular lesions are primarily caused by HSV-1 and genital lesions by HSV2. However, HSV-2 is capable of causing ocular lesions in newborns of HSV-2 infected mothers. In that case, HSV-2 is transmitted to newborns primarily during peripartum period as a result of disrupted membranes, or by direct contact with the mother's vaginal secretions and infected cervix $[3,4]$. These viruses are also capable of causing more serious diseases, such as blindness, meningitis, and encephalitis [5]. HSV-1 is a leading cause of viral corneal blindness and viral encephalitis in developed countries [6,7].

\footnotetext{
* Correspondence: dshukla@uic.edu

${ }^{1}$ Department of Ophthalmology and Visual Sciences, University of Illinois at Chicago, College of Medicine, (1855 W. Taylor), Chicago, IL (60612), USA
} Full list of author information is available at the end of the article
Unlike many herpesviruses, HSV has low species specificity and a wide host range. It has the unparalleled ability to infect human and nonhuman cells alike [8]. The reason behind this successful story of infection is an accumulation of multiple supporting factors. These include:

- Involvement of several multifunctional HSV glycoproteins in entry.

- Existence of multiple alternative receptors. An array of HSV entry receptors for HSV glycoproteins already exists, and evidence suggests even more unidentified HSV receptors.

- Multiple entry modes. HSV has the ability to enter into host cells by direct fusion with the plasma membrane, or via endocytic pathways. The latter can be $\mathrm{pH}$ dependent or independent.

- Multiple spread strategies of HSVs, including: transmission of free virions, movement of HSV along filopodia-like cellular membrane protrusions (surfing) towards the cell body, and lateral cell-to-cell spread.

This review discusses recent advances in the field of HSV entry and highlights the strategies exploited by the virus to infect a wide range of hosts.

\section{HSV structure}

The mature infectious HSV consists of four components from the core outward: an opaque dense core that

\section{Biomed Central}


contains linear double stranded DNA (approximately $152 \mathrm{kB}$ ), encoding at least 74 genes [9]. HSV genome is encapsulated within an icosahedral capsid that consists of 162 capsomeres with six different viral proteins (VPs) present on the surface [10]. The capsid is surrounded by a protein layer called the tegument that contains 22 VPs. Finally, an outer envelope that contains 16 membrane proteins, including 12 different proteins that contain oligosaccharide chains (glycoproteins). These glycoproteins are of particular importance for the purpose of this review since their interactions with the host cell surface proteins mediate HSV entry into the cell. These glycoproteins are: gB, gC, gD, gE, gG, gH, gI, gJ, $\mathrm{gK}, \mathrm{gL}, \mathrm{gM}$, and gN [10-12].

Some of these glycoproteins have been found to exist as heterodimers including the heterodimers $\mathrm{gH}-\mathrm{gL}$ and gE-gI. Many associate with each other, and have the potential to function as oligomeric complexes [13]. In addition, these glycoproteins are suggested to have distinct size, morphology and distribution in the viral envelope, based on studies that have used the electron microscope, and monoclonal antibodies against the viral glycoproteins $\mathrm{gB}, \mathrm{gC}$, and $\mathrm{gD}$. Accordingly, $\mathrm{gB}$ forms the most prominent spikes that are about $14 \mathrm{~nm}$ long with a flattened T-shaped top, invariably clustered in protrusions of the viral envelope. While $\mathrm{gC}$ were up to $24 \mathrm{~nm}$ long distributed randomly, and widely spaced. $\mathrm{gD}$ seemed to be $8-10 \mathrm{~nm}$ long, clustering in a distinct irregular pattern [14].

\section{HSV entry}

HSV entry into host cell is a multistep process that is a result of fusion between the viral envelope and a host cell membrane. It is mediated and modulated by the action of seven HSV glycoproteins along with their interactions with their cognate receptors. These glycoproteins are $\mathrm{gB}, \mathrm{gC}, \mathrm{gD}, \mathrm{gH}, \mathrm{gK}, \mathrm{gL}$, and $\mathrm{gM}$ [1]. However, only four of these glycoproteins $(\mathrm{gB}, \mathrm{gD}, \mathrm{gH}$, and $\mathrm{gL}$ ) are necessary and sufficient to allow virus fusion with the plasma membrane of the host cell (Figure 1) [15-18].

The first step in HSV entry is the attachment of HSV through the envelope glycoproteins $\mathrm{gB}$ and/or $\mathrm{gC}$ to heparan sulfate proteoglycans (HSPG) on the surface of the host cell [19]. The purpose of this interaction is thought to tether the virus to cells in order to concentrate the virus at the cell surface [5]. Although gC enhances HSV binding through its interaction with heparan sulfate (HS), it is not essential for entry [8]. The next step in entry is specific interaction between HSV gD and a gD receptor [20]. Several gD receptors have been identified, and they are discussed in more detail below. This interaction allows for tight anchoring of the virion particle to the plasma membrane of the

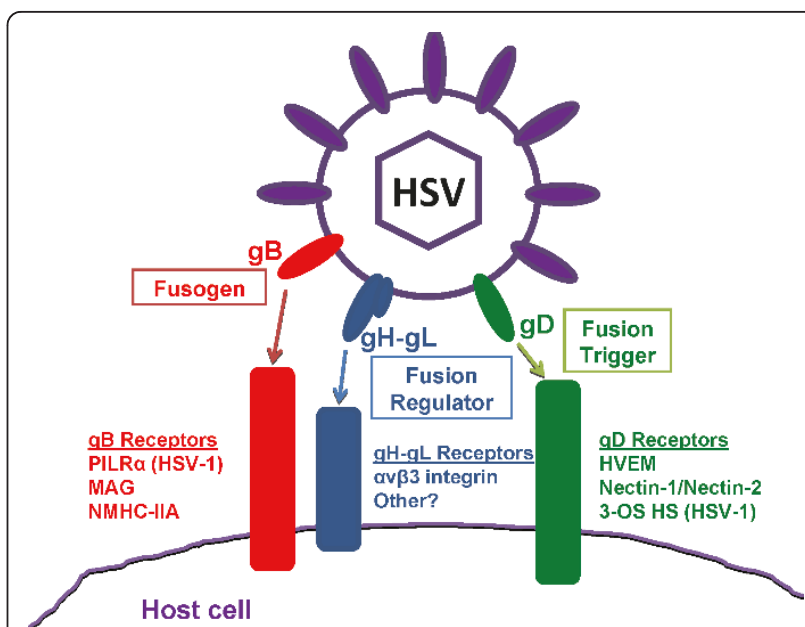

Figure 1 HSV-1 glycoproteins required for viral entry and their identified receptors. HSV-1 entry requires the glycoproteins gB, $\mathrm{gD}$, and the heterodimer $\mathrm{gH}-\mathrm{gL}$. Some of the receptors are exclusive to HSV-1 including PILR $\alpha$ and 3-OS HS.

host cell, and brings both the viral envelope and the cell plasma membrane into close juxtaposition [12]. It is thought that the interaction of gD with one of its receptors triggers a cascade of events that lead to membrane fusion. Structural studies of gD prior to receptor binding and in complex with a receptor suggest that gD undergoes conformational change upon receptor binding, which may transmit an activation signal to $\mathrm{gB}$, and $\mathrm{gH} /$ gL leading to membrane fusion. Thus, fusion requires the formation of a multiprotein complex (a fusogenic complex) comprised of gD, gB, and gH/gL [21-25]. A proline-rich region (PRR) of gD has been shown to be important for this process [26]. Whether this region becomes exposed to contact $\mathrm{gB}$ and $\mathrm{gH} / \mathrm{gL}$ upon receptor binding, or this region functions as a flexible joint to expose an unidentified region is still unknown.

gD crystal structure reveals that its ectodomain consists of a V-like immunoglobulin (IgV) core that is wrapped by two topologically and structurally distinct extensions: $\mathrm{N}$-terminus which has the receptors binding sites, and the $\mathrm{C}$-terminus that has a domain required for triggering viral membrane fusion $[21,27,28]$. Various $\mathrm{gD}$ receptors bind distinct binding sites on the $\mathrm{N}$-terminus [29-31]. Soluble gD has been shown to be sufficient to allow the entry of gD-null virus into the host cell [32]. In addition, soluble forms of gD receptors have been also shown to be sufficient to allow wt virus entry into cells lacking gD receptors [33]. These observations suggest that $\mathrm{gD}$ binding to its receptor is important to modify gD so that it can trigger fusion. A number of studies support the idea that the C-terminus of gD binds to the $\mathrm{N}$-terminus resulting in an autoinhibitory closed conformation. gD receptor binding results in 
conformational change where the C-terminus is displaced adopting an open conformation, and thus activating the fusion machinery $[26,34]$.

Although gB does not promote membrane fusion by itself, its crystal structure reveals that gB share some properties with other class I and class II fusion proteins. $\mathrm{gB}$ belongs to a newly defined class of fusogens: class III. It is a multidomain trimer that is suggested to undergo a complex and ordered refolding process to drive fusion [35]. Currently solved gB structure is predicted to represent the post-fusion conformation of the protein [36]. It possesses five domains and two linker regions in each protomer of the trimeric ectodomain: (Domain I) has the fusion loop, (domain II) is located in the middle, (domain III) is an $\alpha$-helical coild coil that represents the core of the protein, (domain IV) is the crown domain that has the epitopes for HSV specific neutralizing antibodies, and (domain $\mathrm{V}$ ) is the arm domain that consists of a long extension spanning the full length of the protomer and contact to the other two protomers [5,36-38]. The long linker regions are suggested to allow $\mathrm{gB}$ conformational change during fusion.

Some investigators suggest $\mathrm{gH} / \mathrm{gL}$ to have a fusogenic activity by initiating hemifusion [22]. However, a recently resolved crystal structure of $\mathrm{HSV}-2 \mathrm{gH} / \mathrm{gL}$ revealed that $\mathrm{gH} / \mathrm{gL}$ structure does not resemble any known viral fusogen [39]. Moreover, a recent study, using cell fusion assay demonstrated that gD, a gD recptor and $\mathrm{gH} / \mathrm{gL}$ heterodimer are unable to induce hemifusion formation [40]. Consistent with these results, a model was proposed where conformational changes in $\mathrm{gD}$, upon its receptor binding, enable it to activate the heterodimer $\mathrm{gH} / \mathrm{gL}$ into a form that binds to and activates $\mathrm{gB}$ fusogenic activity [41]. Thus $\mathrm{gH} / \mathrm{gL}$ is suggested to act as a regulator of the fusion process by $\mathrm{gB}$ rather than a fusogenic glycoprotein [41]. The interaction of the heterodimer $\mathrm{gH} / \mathrm{gL}$ with $\mathrm{gB}$ does not seem to require the presence of these glycoproteins on the same membrane; since cell-cell fusion has been reported when $\mathrm{gB}$ and $\mathrm{gH}-\mathrm{gL}$ were expressed in trans on different cells [41].

\section{HSPG as an attachment coreceptor}

HSV attachment to HS is the first step of HSV infection. HS is abundantly expressed on the surface of almost all cell types as HSPG. Additionally, the highly sulfated HS possesses negative charges making it suitable to interact with the positively charged viral glycoproteins [42]. Evidence for this interaction stems from the observations that HSV attachment to cell lines that are defective in HS biosynthesis, but not chondroitin sulfate (CS) biosynthesis is reduced by $85 \%$ causing a significant reduction in infectivity in these cell lines [43]. Moreover, soluble heparin, which is closely related to HS, binds
HSV, causing an inhibitory effect on HSV binding to host cells [44]. Enzymatic digestion of HS reduces HSV infection [45].

The viral glycoproteins $\mathrm{gB}$ and $\mathrm{gC}$ are involved in the attachment to HS. The affinity of $\mathrm{gB}$ and $\mathrm{gC}$ to HSPG is different for HSV-1 and HSV-2. While HSV-1 gC has critical role in HSPG attachment during HSV-1 entry, HSV-2 gB is the key glycoprotein for HSV-2 attachment to HSPG $[46,47]$. The difference in HSV-1 and HSV-2 $\mathrm{gB}$ and $\mathrm{gC}$ affinity to HS is suggested to influence several biological activities including sensitivity to polyanionic and polycationic substances [48]. Although viral attachment to HS enhances the infection, the lack of $\mathrm{gC}$ on the viral envelope, or the lack of HS on cells lowers the efficiency of the infection, but does not prevent it $[49,50]$. The lack of gB prevents the infection, primarily because of its critical role during membrane fusion of the virus. In addition to differences between HSV-1 and HSV-2 in the key glycoprotein that interacts with HS during virus attachment, it has been shown that HSV-1 and HSV-2 interact differently with the various structural features of cell surface HS [51]. HS binding can also play a role in the virus's ability to form larger plaques since a mutant virus deleted for a putative HS binding lysine-rich sequence in $\mathrm{gB}$ (residues 68-76) showed reduced plaque sizes [52].

Although the role of HS as an attachment receptor has been intensively studied, little is known about the contribution of the core protein that carries the HS chains. It is known that several families of HSPG have been identified, and one major family is the syndecan family of HSPG [53]. Recently, work from our lab has shown that two members of the syndecan family of HSPG (syndecan-1 and syndecan-2) play a role during HSV entry [54]. The downregulation of these syndecans using specific small interfering RNA (siRNA) resulted in a significant reduction in HSV entry and plaque formation. These results were confirmed using antibodies blocking assay, where antibodies against syndecans were capable of inhibiting viral entry [54]. Interestingly, HSV infection resulted in the upregulation of syndecan-1 and syndecan-2 expression on the cell surface and at the protein level [54]. This observation strongly suggests that these HSPG are involved in the infection, and most probably beyond the attachment step of the infection. Future studies will determine the exact contribution of the various members of the syndecan family in HSV infection. Table 1 lists HSV know entry receptors for some of the tested human cell lines.

\section{gD receptors}

Several lines of evidence suggested that $\mathrm{gD}$ is capable of interacting with a cellular receptor. Firstly, the recognition of a phenomenon called gD-mediated restriction to 
Table 1 HSV known entry receptors for some of the tested human cell lines

\begin{tabular}{|c|c|c|c|}
\hline Cell line & $\begin{array}{l}\text { Major entry } \\
\text { receptor }\end{array}$ & $\begin{array}{l}\text { Other expressed } \\
\text { receptors }\end{array}$ & References \\
\hline Primary human trabecular meshwork (HSV-1) & HVEM & $\begin{array}{l}\text { 3-OST-3 (probably } \\
\text { 3-OS HS) }\end{array}$ & {$[62]$} \\
\hline Primary human corneal fibroblasts (HSV-1) & 3-OS HS & HVEM & [73] \\
\hline Primary human corneal fibroblasts (HSV-2) & HVEM & & [123] \\
\hline Human conjunctival epithelium (HSV-1) & $\begin{array}{l}\text { Nectin-1, } \\
\text { HVEM }\end{array}$ & 3-OS HS & [124] \\
\hline Retinal pigment epithelium (HSV-1) & Nectin-1 & HVEM, 3-OS HS & [96] \\
\hline Human corneal epithelium (HSV-1) & Nectin-1 & HVEM, PILR $\alpha$ & [125] \\
\hline Retinal pigment epithelium (HSV-2) & Nectin-1 & HVEM, PILR $\alpha$ & {$[126]$} \\
\hline Radial glial cells and Cajal-Retzius cells & Nectin-1 & & [127] \\
\hline $\begin{array}{c}\text { Soma and processes of central and peripheral neurons, ependymal cells, choroid plexus } \\
\text { epithelium, vascular endothelium, meningothelial cells (HSV-1, HSV-2) }\end{array}$ & Nectin-1 & & [128] \\
\hline Human Mesenchymal Stem Cells (HSV-1) & 3-OS HS & Nectin-1, HVEM & [129] \\
\hline
\end{tabular}

infection or interference. Cells that constitutively express gD become resistant to infection $[55,56]$. Secondly, truncated soluble form of gD binds to cells until reaching a saturation level [57]. Through generating viral mutants that were able to infect gD expressing cells, the presence of multiple gD receptors was predicted [58]. Currently, there are three classes of gD receptors that belong to structurally unrelated molecular families.

\section{Herpesvirus entry mediator (HVEM)}

Also called herpesvirus entry mediator A (HveA), is the first gD receptor identified through screening HSV resistant cells transfected with human cDNA libraries [59]. HVEM is a member of the tumor necrosis factor (TNF) receptor family and a regulator of immune responses as part of its normal physiological functions [60]. It binds to HSV gD and mediates HSV entry into entry resistant Chinese hamster ovary (CHO) cells $[59,61]$. HVEM is expressed in a variety of cell types including $\mathrm{T}$ and $\mathrm{B}$ lymphocytes, other leucocytes, epithelial cells, fibroblasts and trabecular meshwork and human tissues including the lung, liver, kidney and to less extent in the brain $[19,59,62]$.

\section{Nectin-1 and nectin-2}

They were first described in literature as poliovirus receptor-related protein 1 and 2 (Prr1 and Prr2) and later renamed as $\mathrm{HveC}$ and $\mathrm{HveB}$ and eventually nectin1 and nectin- 2 after the discovery of their roles in cell adhesion [63-67]. These cell surface proteins belong to the four membered nectin family of the immunoglobulin superfamily and only nectin- 1 and nectin- 2 from this family have been shown to mediate HSV entry through their interaction with gD $[61,65,66,68]$.

Nectin-1 has been shown to serve as a receptor for all tested HSV-1 and HSV-2 strains. It is broadly expressed in a wide range of human tissues (e.g. central nervous system (CNS), ganglia, skin, trachea, prostate, thyroid, and liver) and cell lines (e.g. epithelial, endothelial, fibroblastic, keratinocytes, haematopoietic and neuroblastoma) [12]. However, nectin-2, that shares $30 \%$ homology with nectin-1 at the protein level, serves as a receptor only for HSV-2 and some unrestricted HSV-1 mutants that do not exhibit gD-mediated restriction of infection. Nectin-2 is considered a low efficiency receptor; therefore, cells expressing nectin- 2 requires high multiplicity of infection in order to be infected. The reason of that is thought to be a result of weak physical interaction between nectin-2 and gD (HSV-2 gD, or HSV-1 gD mutants) $[66,68]$. Nectin-2 is expressed in numerous human tissues (e.g. placenta, kidney, lung, prostate, pancreas, and thyroid) and human cell lines (e. g. epithelial, endothelial, and neuronal) [12].

\section{3-O-Sulfated heparan sulfate proteoglycan (3-OS HS)}

3-OS HS is a highly sulfated form of HS that has been shown to serve as a HSV-1 gD receptor, but fails to bind to HSV-2 gD [69]. The 3-O-sulfotransferases family of enzymes is responsible for the generation of the 3-Osulfation, where each isoform of these enzyme is capable of generating its unique 3-OS HS. 3-OS HS generated by all the isoforms of the 3-O-sulfotransferases, except for one, are capable of binding gD and mediating virus entry. These enzymes have a distinct expression pattern in cells and tissue making them regulators of HS functions [70].

Using soluble 3-OS HS, it has been shown that 3-OS $\mathrm{HS}$ is capable of triggering not only virus entry, but also HSV-1 induced cell-cell fusion [71]. Furthermore, the downregulation of a prerequisite for the formation of 3OS HS; 2-O-sulfation, was found to significantly inhibit HSV-1 binding, entry and virus induced cell-cell fusion [72]. 3-OS HS is expressed in less variety of tissues and cell lines compared to nectin-1. It is found to be expressed in these tissues: liver, placenta, heart, kidney, and pancreas. It is also expressed by the human 
endothelial cells [12]. In addition, 3-OS HS appears to play a major role in HSV-1 entry into primary cultures of corneal fibroblast [73].

\section{gB receptors}

$\mathrm{gB}$ is known for its role in attaching to HSPG for tethering the virus to the cell surface, as well as its crucial role during membrane fusion of the virus. Although virus attachment to $\mathrm{HS}$ via $\mathrm{gB}$ and $\mathrm{gC}$ enhances the infection, the virus can still infect cells deficient in HS synthesis [74]. Using soluble gB, it has been shown that gB is capable of binding to HSPG deficient cells, and block virus entry, suggesting the presence of a gB receptor [75]. Recently three $\mathrm{gB}$ receptors have been identified where $\mathrm{gB}$ is capable of interacting with these receptors mediating HSV-1 infection.

\section{Paired immunoglobulin-like type 2 receptor- $\alpha$ (PILR $\alpha)$}

PILR is one of the paired receptor families. It is expressed mainly in immune cells where one receptor in the family has activating function, while another receptor in the family mediates inhibitory functions. While inhibitory receptors generally recognize self-antigens such as MHC molecules, activating receptors do not recognize self-antigens. Pathogens may utilize the inhibitory receptors to evade the immune system. PILR $\alpha$ has an immunoreceptor tyrosine-based inhibition motif (ITIM) that delivers inhibitory effects. Expression of PILR $\alpha$ in HSV resistant $\mathrm{CHO}$ cells renders these cells susceptible to the virus. Moreover, treating susceptible cells with anti-PILR $\alpha$ or anti-HVEM blocked HSV-1 infection, indicating that both $\mathrm{gB}$ receptor and $\mathrm{gD}$ receptor are required for HSV infection [76]. Interestingly, PILR $\alpha$ has been shown to confer susceptibility to HSV-1 entry, as well as other alphaherpesviruses, including pseudorabies virus, but not HSV-2 into HSV resistant $\mathrm{CHO}$ cells [77]. The association of PILR $\alpha$ with HSV-1 gB depends on the presence of sialylated O-glycans on $\mathrm{gB}$ with two threonine residues on $\mathrm{gB}$ found to be essential for principal O-glycans addition to gB [78].

\section{Myelin-associated glycoprotein (MAG)}

MAG (also called Sialic-acid-binding Ig-like lectin (Siglec)) is another paired receptor that has $5-12 \%$ homology with PILR $\alpha$ [79]. It is localized in the periaxonal space in glial cells suggesting its importance in regulating myelin-axon interactions, including myelination, initiation, and myelin integrity maintenance. Using MAG-/- mice, MAG has been shown to function as an inhibitor of axonal regeneration [80]. MAG associates with HSV-1 gB as well as varicella-zoster virus (VZV) $\mathrm{gB}$ and confers susceptibility to HSV-1 and VZV in MAG-transfected promyelocytes and oligodendroglial cells respectively [79]. Since MAG is not naturally expressed in epithelial cells and neuronal cells which are considered prime targets for $\mathrm{HSV}-1$ and VZV, MAG is not thought to serve as a major receptor for these viruses. However, both HSV-1 and VZV infect glial cells in the acute phase of infection, suggesting that MAG might be involved in the neurological disorders caused by HSV-1 and VZV.

\section{Non-muscle myosin heavy chain IIA (NMHC-IIA)}

NM II binds to actin and has actin cross-linking and contractile characteristics. It is a key protein in the control of many events that are involved in cell reshaping and movement; including cell migration, cell adhesion and cell division. NM-II is composed of two heavy chains, two regulatory light chains, and two essential light chains. NM IIA is one isoform of the NM II protein [81]. NMHC-IIA was identified as an HSV-1 gB receptor using a tandem affinity-purification approach with a membrane-impermeable crosslinker coupled with mass-spectrometry-based proteomics technology [82].

NMHC-IIA has been shown to physically interact with HSV-1 gB, and mediate HSV-1 infectivity both in vitro and in vivo. Human promyelocytic HL60 cells stably expressing high levels of NMHC-IIA exhibited a significantly higher susceptibility to HSV-1 infection compared to cells expressing low levels of NMHC-IIA. NMHC-IIA role as an entry receptor was also exhibited in naturally permissive cells that express NMHC-IIA endogenously. NMHC-IIA functions primarily in the cytoplasm. However, interestingly, NMHC-IIA cell surface expression was shown to be induced after HSV-1 adsorption at $4^{\circ} \mathrm{C}$ that was followed by a shift in temperature to $37^{\circ} \mathrm{C}$ [82]. While PILR $\alpha$ and MAG expression is limited to certain types of cells, NMHC-IIA is ubiquitously expressed in numerous human tissues and cell types, suggesting its important role as the functional HSV-1 gB receptor [81,82].

HSV entry has been closely associated with actincytoskeleton reorganization [83]. For example, it has been shown that HSV exposure induces the formation of filopodia-like cell membrane protrusions, on which HSV has the ability to bind and move toward the cell body. This movement of HSV on filopodia is termed surfing, and believed to be a spread strategy of the virus. In addition, HSV glycoprotein $\mathrm{gB}$ was found to be critical for virus surfing [84]. Since NMHC-IIA binds to actin, and is involved in many events controlling cell movement and reshaping, it is quite possible that virus surfing on filopodia is mediated by $\mathrm{gB}$ binding to NMHC-IIA. More studies are needed to investigate the contribution of NMHC-IIA in virus surfing.

\section{Lipid-raft associated $g B$ receptor}

An HSV gB lipid-raft-associated receptor has also been proposed by the observation that $\mathrm{gB}$, but not $\mathrm{gC}, \mathrm{gD}$, or $\mathrm{gH}$ associates with glycolipid-enriched membranes (DIG) that represent raft-containing fractions. Since gC does not associate with DIG, gB association with DIG is 
suggested to be either heparan sulfate independent, or heparan sulfate dependent where $\mathrm{gB}$ is associating with specific type of HSPG, or has a differential effect compared to gC association with HSPG [85].

\section{gH-gL receptors}

Many lines of evidence support the presence of $\mathrm{gH}-\mathrm{gL}$ receptor; nevertheless, the contribution of this gH-gLreceptor interaction to HSV infection is not yet fully understood. An observation was made in our lab where the cellular expression of $\mathrm{gH}$-gL confers resistance to HSV-1 entry, indicating that gH-gL on the cell surface may result in sequestering the available cellular gH-gL receptor, perturbing the entry process of the virus [86]. Soluble gH-gL has been shown to bind to $\alpha \mathrm{v} \beta 3$ integrin through a potential integrin-binding motif, Arg-Gly-Asp (RGD), in gH [87]. However, mutating RGD to triple RGE (Arg-Gly-Glu) does not affect HSV-1 entry [88]. gH-gL was also found to bind to cells independently of $\alpha v \beta 3$, and that binding was found to be important for HSV entry and membrane fusion [89]. Additional studies are important to identify the presence, and understand the significance of possible gH receptors during HSV infection.

\section{B5 protein}

Using expression cloning, $h f l$-B5 gene was isolated that encodes a cellular protein found to be involved in HSV infection. B5 is a type- 2 membrane protein that has an extracellular heptad repeat potentially capable of forming an $\alpha$-helix for coiled-coils. B5 is ubiquitously expressed on many human cell lines. Transfecting porcine renal epithelial cells that are naturally resistant to HSV rendered these cells susceptible to the virus, which made B5 protein a candidate HSV receptor [90]. It was proposed that B5 $\alpha$-helix might interact with viral proteins containing $\alpha$-helices such as $\mathrm{gH}$ to facilitate membrane fusion. However, a recent study revealed that B5 role in HSV infection is not during HSV entry, but during HSV proteins translation. B5 silencing did not affect entry markers including intracellular viral capsids delivery and viral tegument protein nuclear transport. On the other hand, B5 silencing was found to inhibit viral immediate early proteins translation [91].

\section{The design of new antivirals utilizing HSV receptors}

Advances in the field of HSV receptors provide new strategies for the generation of anti-HSV agents. Experiments done to identify the major HSV entry receptor in various cell types have exploited assays including antibody blocking assays, and the down regulation of HSV receptors utilizing siRNA [2,62,73]. These assays indicated that HSV infection can be inhibited by blocking the viral entry receptors. Copeland and colleagues have generated a 3-OS HS octasaccharide that has the ability to inhibit HSV-1 entry [92]. Recently, our lab has isolated 12-mer peptides that bind specifically to HS, or 3OS HS, and block HSV-1 entry. Interestingly, peptides isolated against 3-OS HS exhibited the ability to inhibit the entry of not only HSV-1, but also some divergent members of herpesvirus family including cytomegalovirus (CMV) and human herpesvirus-8 (HHV-8) [93].

\section{HSV entry modes}

Recent studies have shown that HSV can follow different entry routes. Two major entry routes include: (I) a $\mathrm{pH}$ independent fusion with the plasma membrane of the host cell (II) endocytosis that may be phagocytosislike where the virus triggers the fusion with the phagocytic membrane $[83,94]$. This entry route may not always be $\mathrm{pH}$ dependent. Although all HSV glycoproteins function at neutral and low $\mathrm{pH}, \mathrm{gB}$ undergoes minor conformational changes under low $\mathrm{pH}$, the consequences of these changes are not yet known [95]. Antiacidification drugs such as bafilomycin A enable the identification of $\mathrm{pH}$ dependence during endocytosis.

The differential entry route that HSV can follow is cell type-specific. For example, HeLa, human retinal pigment epithelial cells (RPE), and the $\mathrm{CHO}$ cell line expressing nectin-1 gD receptor allow HSV entry through low $\mathrm{pH}$ endocytic pathway. However, the monkey kidney epithelial cells (vero) allow HSV entry through the direct fusion with plasma membrane of the host cell $[96,97]$. Regardless of the entry route followed, HSV enters host cells by inducing fusion between the viral envelope and the host cell membrane.

Very little is known about what causes these differential entry routes. Since it is cell type specific, it is suggested that cellular determinants are responsible for choosing the viral entry route into the host cell. The contribution of $\mathrm{gD}$ receptors in determining the entry mode is elusive. One study has shown that co-culturing cells expressing gD with cells expressing nectin-1 resulted in the downregulation of nectin-1 in cells where HSV enters by endocytosis but not in cells where HSV enters at the plasma membrane. This suggested that $\mathrm{gD}$ mediated internalization of nectin-1 directs HSV to an endocytic mode of entry to cells [98]. Also, a mutant HSV strain enters CHO-nectin-1 cells via the endocytic pathway, but fuses at the plasma membrane of CHO-nectin-2 cells [99]. On the other hand, in another study, ${ }^{35} \mathrm{~S}-\mathrm{HSV}$ uptake from the surface of CHO-nectin-1 cells was similar to that of $\mathrm{CHO}$ cells that lack any known gD receptors, indicating that the presence of nectin-1 does not promote endocytic uptake of HSV into CHO cells [100].

Recently, several other cellular determinants have been suggested to be involved in determining HSV entry 
route. The gB receptor PILR $\alpha$ is one of these cellular determinant, where it is found to direct HSV to the fusion at the plasma membrane mode of entry. While $\mathrm{HSV}$ uptake to $\mathrm{CHO}$ cells and $\mathrm{CHO}$-nectin-1 cells is mediated by endocytosis, HSV entry into $\mathrm{CHO}$ cells expressing PILR $\alpha$ was found to be mediated by fusion at the cell surface [77]. Suggesting that an alternative entry mode for HSV was produced by the expression of the gB receptor PILR $\alpha$. The integrin $\alpha v \beta 3$ was also found to be involved in directing the viral route of entry. Overexpressing $\alpha v \beta 3$ in $\mathrm{CHO}$-nectin-1 cells, that naturally lack $\alpha v \beta 3$, modifies the route of entry to an acidic compartment dependent on cholesterol-rich rafts and dynamin 2 . Moreover, overexpressing $\alpha \mathrm{v} \beta 3$ in J-nectin- 1 and 293T cells modifies the route of HSV entry from neutral compartments to acidic compartments dependent on cholesterol-rich rafts and dynamin2 [101].

\section{HSV successful infection of various hosts}

Although HSV is considered a human herpesvirus, it has a wide species host range, and thus has the ability to infect animals and cell cultures of various species [12]. There are reports of HSV experimentally infecting mice, rabbits, guinea pigs, zebrafish, and cultured MadinDarby canine kidney (MDCK) cells [102-106]. The ability to experimentally infect non-habitual species by HSV suggests that HSV entry requirements, including the various receptors and entry modes, are quite commonly available and accessible on the cells of various host species.

Another point that might explain HSV broad species host range is that HSV can exploit, as receptors, animal homologues of HSV receptors. For example, the murine homologue of human nectin- $1 \delta$ isoform has a $>90 \%$ identity with its human counterpart, and act as a species non-specific entry receptor of HSV, pseudorabies virus (PrV), and bovine herpesvirus-1 (BHV-1). Interestingly, soluble murine nectin- $1 \delta$ does not bind HSV gD at a detectable level, although it interacts physically with the virion [107]. On the other hand, the murine homologue of human nectin-1 was found to be capable of mediating PrV entry, but not HSV entry [108]. Other examples are the murine and zebrafish homologs of the 3-O-sulfotransferases enzymes responsible for modifying HS generating the HSV-1 gD receptor 3-OS HS $[109,110]$. Interestingly, the expression of the zebrafish homolog of 3-O-sulfotransferase-3 isoform into the entry resistant $\mathrm{CHO}$ cells and zebrafish fibroblasts has been shown to mediate HSV-1 entry and spread [111].

Various species that are susceptible to HSV provide important animal models for HSV research. The mouse model has been widely used in HSV entry, pathogenesis and anti-viral research, while guinea pigs and rabbits are suitable animal models for HSV latency research [112].
Since zebrafish has a fully developed immune system, it has been suggested that this animal model be utilized to study HSV interactions with the immune system [105]. These various specious have been infected experimentally for research purposes, most of them are not naturally infected with HSV. However, there are some rare cases where some of these animals get the infection naturally. For example, there are two reported cases of rabbits naturally infected with HSV-1 leading to encephalitis [113,114].

An important application of HSV animal models is the development of an effective therapeutic anti-herpetic vaccine capable of inhibiting viral reactivation. Several studies have suggested that a crucial element for the generation of anti-herpetic vaccine, is a cellular response specific to HSV, where Interferon- $\gamma(+)(\operatorname{IFN}-\gamma(+)) \mathrm{CD}^{+}$ $\mathrm{T}$ cells seem to suppress spontaneous reactivation of the latent virus $[115,116]$. The mouse model has been extensively utilized to study the various aspects of HSV infection, including virus entry and replication $[117,118]$. Although HSV establishes latency in mice neural tissues and reactivates upon stimulation, spontaneous sporadic viral reactivation does not occur in mice $[119,120]$. This is an important point for the development of anit-HSV vaccine, since HSV reactivation may result in serious diseases including the blinding herpetic keratitis. Therefore, it has been suggested that the mouse model is not the suitable model for studying the effectiveness of anti-HSV vaccines that inhibit viral reactivation [121]. Two other animal models have been suggested to study the effectiveness of anti-HSV vaccine that inhibits spontaneous viral reactivation: rabbit and genie pig. HSV is capable of establishing latent infection in these animal models, and reactivate spontaneously causing disease, similar to HSV infection in human [121]. Recently, a Human Leukocyte Antigen (HLA) transgenic rabbit model has been introduced for preclinical evaluation of human CD8(+) T cell epitope-based vaccines against ocular HSV infection [122].

\section{Conclusions}

The ability of HSV to productively infect a wide range of hosts and cell types suggests that HSV has evolved to use multiple receptors and pathways to facilitate entry into multiple cell types. Regardless of HSV entry receptors or pathways utilized, HSV entry into host cell has common features among various routes of virus entry, including HSV fusion with the plasma membrane of the host cell. This indicates that HSV might recognize structural features of receptors that are conserved among various human and animal cell types. The presence of multiple entry receptors and pathways could be the reason of the wide range of hosts and cell types that can be infected by HSV. However this does not answer 
questions like: what dictates the utilized entry pathway and cellular receptors by HSV? This is particularly important in situations where more than one entry receptor is available for the virus to use on the host cell surface. Moreover, do the various combinations of $\mathrm{gB}$ and gD receptors utilized by HSV affect the entry and/ or the infection process? Answers to such questions require conducting more studies to fully understand the process of HSV entry into host cell.

Recent advances in the field of HSV cellular receptors and HSV entry glycoproteins' structures, interactions and functions have broadened our understanding of HSV entry into the cell. Such advances will definitely help in the process of developing potent HSV vaccines and anti-HSV drugs. The huge prevalence of HSV in the human population worldwide which increases the risk of acquiring HSV related diseases, including blindness, genital herpes, encephalitis, meningitis, especially in immune compromised patients and infants, urges for such development in the anti-HSV therapies.

\begin{abstract}
Abbreviations
BHV-1: bovine herpesvirus-1; CHO: Chinese hamster ovary; CMV: Cytomegalovirus; CNS: central nervous system; CS: chondroitin sulfate; DIG: glycolipid-enriched membranes; gB-gN: glycoprotein B-N; HHV-8: Human herpesvirus-8; HLA: Human Leukocyte Antigen; HS: heparan sulfate; HSPG: heparan sulfate proteoglycans; HSV-1 and HSV-2: Herpes simplex virus type-1 and type-2; HveA: herpesvirus entry mediator A; HveB: herpesvirus entry mediator $\mathrm{B}$; HveC: herpesvirus entry mediator $C_{;}$HVEM: Herpesvirus entry mediator; IFN: Interferon; IgV: V-like immunoglobulin; ITIM: immunoreceptor tyrosine-based inhibition motif; MAG: Myelin-associated glycoprotein; MDCK: Madin-Darby canine kidney; NMHC-IIA: Non-muscle myosin heavy chain IIA; PILRa: paired immunoglobulin-like type 2 receptor-a; PRR: proline-rich region; Prr1 and Prr2: poliovirus receptor-related protein 1 and 2; PrV: pseudorabies virus; RPE: retinal pigment epithelial cells; Siglec: Sialic-acidbinding Ig-like lectin; siRNA: small interfering RNA; TNF: tumor necrosis factor; VPS: viral proteins; VZV: varicella-zoster virus; 3-OS HS: 3-O-Sulfated heparan sulfate proteoglycan; 3-OST-3: 3-O-sulfotransferases isoform 3
\end{abstract}

\section{Acknowledgements}

The authors are supported by NIH grants Al057860 (DS), Al081869 (DS), and a Core Grant EY01792.

\section{Author details}

'Department of Ophthalmology and Visual Sciences, University of Illinois at Chicago, College of Medicine, (1855 W. Taylor), Chicago, IL (60612), USA. ${ }^{2}$ Department of Microbiology and Immunology, University of Illinois at Chicago, College of Medicine, Chicago, (835 S. Wolcott) IL (60612), USA.

\section{Authors' contributions}

GK and DS contributed to and edited the manuscript. Both authors read and approved the final manuscript.

\section{Competing interests}

The authors declare that they have no competing interests.

Received: 4 August 2011 Accepted: 26 October 2011

Published: 26 October 2011

\section{References}

1. Heldwein $E E$, Krummenacher $C:$ Entry of herpesviruses into mammalian cells. Cell Mol Life Sci 2008, 65(11):1653-1668.
2. Akhtar J, Shukla D: Viral entry mechanisms: cellular and viral mediators of herpes simplex virus entry. FEBS J 2009, 276(24):7228-7236.

3. Annunziato PW, Gershon A: Herpes simplex virus infections. Pediatr Rev 1996, 17(12):415-423.

4. Jacobs RF: Neonatal herpes simplex virus infections. Semin Perinatol 1998, 22(1):64-71.

5. Connolly SA, Jackson JO, Jardetzky TS, Longnecker R: Fusing structure and function: a structural view of the herpesvirus entry machinery. Nat Rev Microbiol 2011, 9(5):369-381.

6. Herpetic Eye Disease Study Group: Acyclovir for the prevention of recurrent herpes simplex virus eye disease. N Engl J Med 1998, 339:300-306.

7. Shoji H, Azuma K, Nishimura Y, Fujimoto H, Sugita Y, Eizuru Y: Acute viral encephalitis: the recent progress. Intern Med 2002, 41(6):420-428.

8. Spear PG, Longnecker R: Herpesvirus entry: an update. J Virol 2003 , 77(19):10179-10185.

9. McGeoch DJ, Rixon FJ, Davison AJ: Topics in herpesvirus genomics and evolution. Virus Res 2006, 117(1):90-104

10. Diefenbach RJ, Miranda-Saksena M, Douglas MW, Cunningham AL: Transport and egress of herpes simplex virus in neurons. Rev Med Virol 2008, 18(1):35-51.

11. Mettenleiter TC: Budding events in herpesvirus morphogenesis. Virus Res 2004, 106(2):167-180

12. Campadelli-Fiume G, Cocchi F, Menotti L, Lopez M: The novel receptors that mediate the entry of herpes simplex viruses and animal alphaherpesviruses into cells. Rev Med Virol 2000, 10(5):305-319.

13. Handler CG, Eisenberg RJ, Cohen GH: Oligomeric structure of glycoproteins in herpes simplex virus type 1.J Virol 1996, 70(9):6067-6070.

14. Stannard LM, Fuller AO, Spear PG: Herpes simplex virus glycoproteins associated with different morphological entities projecting from the virion envelope. J Gen Virol 1987, 68(Pt 3):715-725.

15. Turner A, Bruun B, Minson T, Browne H: Glycoproteins gB, gD, and $g \mathrm{HgL}$ of herpes simplex virus type 1 are necessary and sufficient to mediate membrane fusion in a Cos cell transfection system. J Virol 1998, 72(1):873-875.

16. Pertel PE, Fridberg A, Parish ML, Spear PG: Cell fusion induced by herpes simplex virus glycoproteins $\mathrm{gB}, \mathrm{gD}$, and $\mathrm{gH}$-gL requires a $\mathrm{gD}$ receptor but not necessarily heparan sulfate. Virology 2001, 279(1):313-324.

17. Muggeridge MI: Characterization of cell-cell fusion mediated by herpes simplex virus 2 glycoproteins $\mathrm{gB}, \mathrm{gD}, \mathrm{gH}$ and $\mathrm{gL}$ in transfected cells. $J$ Gen Virol 2000, 81(Pt 8):2017-2027.

18. Campadelli-Fiume G, Amasio M, Avitabile E, Cerretani A, Forghieri C, Gianni T, Menotti L: The multipartite system that mediates entry of herpes simplex virus into the cell. Rev Med Virol 2007, 17(5):313-326.

19. Spear PG: Herpes simplex virus: receptors and ligands for cell entry. Cell Microbiol 2004, 6(5):401-410.

20. Shukla D, Spear PG: Herpesviruses and heparan sulfate: an intimate relationship in aid of viral entry. J Clin Invest 2001, 108(4):503-510.

21. Carfi A, Willis SH, Whitbeck JC, Krummenacher C, Cohen GH, Eisenberg RJ, Wiley DC: Herpes simplex virus glycoprotein D bound to the human receptor HveA. Mol Cell 2001, 8(1):169-179.

22. Subramanian RP, Geraghty RJ: Herpes simplex virus type 1 mediates fusion through a hemifusion intermediate by sequential activity of glycoproteins D, H, L, and B. Proc Natl Acad Sci USA 2007, 104(8):2903-2908.

23. Gianni T, Amasio M, Campadelli-Fiume G: Herpes simplex virus $\mathrm{gD}$ forms distinct complexes with fusion executors $\mathrm{gB}$ and $\mathrm{gH} / \mathrm{gL}$ in part through the C-terminal profusion domain. J Biol Chem 2009, 284(26):17370-17382.

24. Atanasiu D, Whitbeck JC, Cairns TM, Reilly B, Cohen GH, Eisenberg RJ: Bimolecular complementation reveals that glycoproteins $\mathrm{gB}$ and $\mathrm{gH} / \mathrm{gL}$ of herpes simplex virus interact with each other during cell fusion. Proc Natl Acad Sci USA 2007, 104(47):18718-18723.

25. Avitabile E, Forghieri C, Campadelli-Fiume G: Complexes between herpes simplex virus glycoproteins $\mathrm{gD}, \mathrm{gB}$, and $\mathrm{gH}$ detected in cells by complementation of split enhanced green fluorescent protein. $J$ Virol 2007, 81(20):11532-11537.

26. Fusco D, Forghieri C, Campadelli-Fiume G: The pro-fusion domain of herpes simplex virus glycoprotein $\mathrm{D}(\mathrm{gD})$ interacts with the $\mathrm{gD} N$ terminus and is displaced by soluble forms of viral receptors. Proc Natl Acad Sci USA 2005, 102(26):9323-9328. 
27. Whitbeck JC, Muggeridge MI, Rux AH, Hou W, Krummenacher C, Lou H, van Geelen A, Eisenberg RJ, Cohen GH: The major neutralizing antigenic site on herpes simplex virus glycoprotein $\mathrm{D}$ overlaps a receptor-binding domain. J Virol 1999, 73(12):9879-9890.

28. Zago A, Jogger $C R$, Spear PG: Use of herpes simplex virus and pseudorabies virus chimeric glycoprotein D molecules to identify regions critical for membrane fusion. Proc Natl Acad Sci USA 2004, 101(50):17498-17503

29. Whitbeck JC, Connolly SA, Willis SH, Hou W, Krummenacher C, Ponce de Leon M, Lou H, Baribaud I, Eisenberg RJ, Cohen GH: Localization of the gD-binding region of the human herpes simplex virus receptor, HveA. $J$ Virol 2001, 75(1):171-180

30. Yoon M, Zago A, Shukla D, Spear PG: Mutations in the $\mathbf{N}$ termini of herpes simplex virus type 1 and $2 \mathrm{gDs}$ alter functional interactions with the entry/fusion receptors HVEM, nectin-2, and 3-O-sulfated heparan sulfate but not with nectin-1. J Virol 2003, 77(17):9221-9231.

31. Manoj S, Jogger CR, Myscofski D, Yoon M, Spear PG: Mutations in herpes simplex virus glycoprotein $D$ that prevent cell entry via nectins and alter cell tropism. Proc Natl Acad Sci USA 2004, 101(34):12414-12421.

32. Cocchi F, Fusco D, Menotti L, Gianni T, Eisenberg RJ, Cohen GH, Campadelli-Fiume G: The soluble ectodomain of herpes simplex virus gD contains a membrane-proximal pro-fusion domain and suffices to mediate virus entry. Proc Natl Acad Sci USA 2004, 101(19):7445-7450.

33. Kwon H, Bai Q, Baek HJ, Felmet K, Burton EA, Goins WF, Cohen JB, Glorioso JC: Soluble $V$ domain of Nectin-1/HveC enables entry of herpes simplex virus type 1 (HSV-1) into HSV-resistant cells by binding to viral glycoprotein D. J Virol 2006, 80(1):138-148.

34. Krummenacher C, Supekar VM, Whitbeck JC, Lazear E, Connolly SA, Eisenberg RJ, Cohen GH, Wiley DC, Carfi A: Structure of unliganded HSV gD reveals a mechanism for receptor-mediated activation of virus entry. EMBO J 2005, 24(23):4144-4153

35. Heldwein EE, Lou H, Bender FC, Cohen GH, Eisenberg RJ, Harrison SC: Crystal structure of glycoprotein B from herpes simplex virus 1. Science 2006, 313(5784):217-220

36. Lin $E$, Spear PG: Random linker-insertion mutagenesis to identify functional domains of herpes simplex virus type 1 glycoprotein B. Proc Natl Acad Sci USA 2007, 104(32):13140-13145.

37. Hannah BP, Cairns TM, Bender FC, Whitbeck JC, Lou H, Eisenberg RJ, Cohen GH: Herpes simplex virus glycoprotein B associates with target membranes via its fusion loops. J Virol 2009, 83(13):6825-6836.

38. Galdiero S, Vitiello M, D'Isanto M, Falanga A, Cantisani M, Browne H, Pedone C, Galdiero M: The identification and characterization of fusogenic domains in herpes virus glycoprotein B molecules. Chembiochem 2008, 9(5):758-767.

39. Chowdary TK, Cairns TM, Atanasiu D, Cohen GH, Eisenberg RJ, Heldwein EE: Crystal structure of the conserved herpesvirus fusion regulator complex gH-gL. Nat Struct Mol Biol 2010, 17(7):882-888.

40. Jackson JO, Longnecker R: Reevaluating herpes simplex virus hemifusion. J Virol 2010, 84(22):11814-11821.

41. Atanasiu D, Saw WT, Cohen GH, Eisenberg RJ: Cascade of events governing cell-cell fusion induced by herpes simplex virus glycoproteins gD, gH/gL, and gB. J Virol 2010, 84(23):12292-12299.

42. Trybala E, Liljeqvist JA, Svennerholm B, Bergström T: Herpes simplex virus types 1 and 2 differ in their interaction with heparan sulfate. J Virol 2000, 74(19):9106-9114.

43. Gruenheid S, Gatzke L, Meadows H, Tufaro F: Herpes simplex virus infection and propagation in a mouse $\mathrm{L}$ cell mutant lacking heparan sulfate proteoglycans. J Virol 1993, 67(1):93-100.

44. Nahmias AJ, Kibrick S: Inhibitory effect of heparin on herpes simplex virus. J Bacteriol 1964, 87(5):1060-1066.

45. WuDunn D, Spear PG: Initial interaction of herpes simplex virus with cells is binding to heparan sulfate. J Virol 1989, 63(1):52-58.

46. Gerber SI, Belval BJ, Herold BC: Differences in the role of glycoprotein C of HSV-1 and HSV-2 in viral binding may contribute to serotype differences in cell tropism. Virology 1995, 214(1):29-39.

47. Cheshenko N, Herold BC: Glycoprotein B plays a predominant role in mediating herpes simplex virus type 2 attachment and is required for entry and cell-to-cell spread. J Gen Virol 2002, 83(Pt 9):2247-2255.

48. Langeland N, Holmsen $H$, Lillehaug JR, Haarr L: Evidence that neomycin inhibits binding of herpes simplex virus type 1 to the cellular receptor. $J$ Virol 1987, 61(11):3388-3393.
49. Herold BC, Visalli RJ, Susmarski N, Brandt CR, Spear PG: Glycoprotein Cindependent binding of herpes simplex virus to cells requires cell surface heparan sulphate and glycoprotein B. J Gen Virol 1994, 75(Pt 6):1211-1222.

50. Herold BC, Spear PG: Neomycin inhibits glycoprotein C (gC)-dependent binding of herpes simplex virus type 1 to cells and also inhibits postbinding events in entry. Virology 1994, 203(1):166-171.

51. Herold BC, Gerber SI, Belval BJ, Siston AM, Shulman N: Differences in the susceptibility of herpes simplex virus types 1 and 2 to modified heparin compounds suggest serotype differences in viral entry. J Virol 1996, 70(6):3461-3469.

52. Laquerre $S$, Argnani $R$, Anderson DB, Zucchini $S$, Manservigi R, Glorioso JC: Heparan sulfate proteoglycan binding by herpes simplex virus type 1 glycoproteins $B$ and $C$, which differ in their contributions to virus attachment, penetration, and cell-to-cell spread. J Virol 1998, 72(7):6119-6130

53. Tumova S, Woods A, Couchman JR: Heparan sulfate proteoglycans on the cell surface: versatile coordinators of cellular functions. Int J Biochem Cell Biol 2000, 32(3):269-288.

54. Bacsa S, Karasneh G, Dosa S, Liu J, Valyi-Nagy T, Shukla D: Syndecan-1 and syndecan-2 play key roles in herpes simplex virus type-1 infection. $J$ Gen Virol 2011, 92(Pt 4):733-743.

55. Campadelli-Fiume G, Arsenakis M, Farabegoli F, Roizman B: Entry of herpes simplex virus 1 in $B J$ cells that constitutively express viral glycoprotein $D$ is by endocytosis and results in degradation of the virus. J Virol 1988, 62(1):159-167.

56. Johnson RM, Spear PG: Herpes simplex virus glycoprotein D mediates interference with herpes simplex virus infection. J Virol 1989, 63(2):819-827.

57. Johnson DC, Burke RL, Gregory T: Soluble forms of herpes simplex virus glycoprotein $D$ bind to a limited number of cell surface receptors and inhibit virus entry into cells. J Virol 1990, 64(6):2569-2576.

58. Brandimarti R, Huang T, Roizman B, Campadelli-Fiume G: Mapping of herpes simplex virus 1 genes with mutations which overcome host restrictions to infection. Proc Natl Acad Sci USA 1994, 91(12):5406-5410.

59. Montgomery RI, Warner MS, Lum BJ, Spear PG: Herpes simplex virus-1 entry into cells mediated by a novel member of the TNF/NGF receptor family. Cell 1996, 87(3):427-436.

60. Croft M: Co-stimulatory members of the TNFR family: keys to effective Tcell immunity? Nat Rev Immunol 2003, 3(8):609-620.

61. Krummenacher C, Nicola AV, Whitbeck JC, Lou H, Hou W, Lambris JD, Geraghty RJ, Spear PG, Cohen GH, Eisenberg RJ: Herpes simplex virus glycoprotein $D$ can bind to poliovirus receptor-related protein 1 or herpesvirus entry mediator, two structurally unrelated mediators of virus entry. J Virol 1998, 72(9):7064-7074.

62. Tiwari V, Clement C, Scanlan PM, Kowlessur D, Yue BY, Shukla D: A role for herpesvirus entry mediator as the receptor for herpes simplex virus 1 entry into primary human trabecular meshwork cells. J Virol 2005, 79(20):13173-13179

63. Eberlé F, Dubreuil P, Mattei MG, Devilard E, Lopez M: The human PRR2 gene, related to the human poliovirus receptor gene (PVR), is the true homolog of the murine MPH gene. Gene 1995, 159(2):267-272.

64. Lopez M, Eberlé F, Mattei MG, Gabert J, Birg F, Bardin F, Maroc C, Dubreuil P: Complementary DNA characterization and chromosomal localization of a human gene related to the poliovirus receptorencoding gene. Gene 1995, 155(2):261-265.

65. Geraghty RJ, Krummenacher C, Cohen GH, Eisenberg RJ, Spear PG: Entry of alphaherpesviruses mediated by poliovirus receptor-related protein 1 and poliovirus receptor. Science 1998, 280(5369):1618-1620.

66. Warner MS, Geraghty RJ, Martinez WM, Montgomery RI, Whitbeck JC, Xu R, Eisenberg RJ, Cohen GH, Spear PG: A cell surface protein with herpesvirus entry activity (HveB) confers susceptibility to infection by mutants of herpes simplex virus type 1 , herpes simplex virus type 2 , and pseudorabies virus. Virology 1998, 246(1):179-189.

67. Takai $Y$, Nakanishi $\mathrm{H}$ : Nectin and afadin: novel organizers of intercellular junctions. J Cell Sci 2003, 116(Pt 1):17-27.

68. Lopez M, Cocchi F, Menotti L, Avitabile E, Dubreuil P, Campadelli-Fiume G: Nectin2alpha (PRR2alpha or HveB) and nectin2delta are low-efficiency mediators for entry of herpes simplex virus mutants carrying the Leu25Pro substitution in glycoprotein D. J Virol 2000, 74(3):1267-1274. 
69. Shukla D, Liu J, Blaiklock P, Shworak NW, Bai X, Esko JD, Cohen GH, Eisenberg RJ, Rosenberg RD, Spear PG: A novel role for 3-O-sulfated heparan sulfate in herpes simplex virus 1 entry. Cell 1999, 99(1):13-22.

70. O'Donnell CD, Shukla D: The Importance of Heparan Sulfate in Herpesvirus Infection. Virol $\operatorname{Sin} 2008,23(6): 383-393$.

71. Tiwari V, O'donnell C, Copeland RJ, Scarlett T, Liu J, Shukla D: Soluble 3-Osulfated heparan sulfate can trigger herpes simplex virus type 1 entry into resistant Chinese hamster ovary (CHO-K1) cells. J Gen Virol 2007, 88(Pt 4):1075-1079.

72. O'Donnell CD, Kovacs M, Akhtar J, Valyi-Nagy T, Shukla D: Expanding the role of 3-O sulfated heparan sulfate in herpes simplex virus type-1 entry. Virology 2010, 397(2):389-398.

73. Tiwari V, Clement C, Xu D, Valyi-Nagy T, Yue BY, Liu J, Shukla D: Role for 3O-sulfated heparan sulfate as the receptor for herpes simplex virus type 1 entry into primary human corneal fibroblasts. J Virol 2006, 80(18):8970-8980.

74. Banfield BW, Leduc Y, Esford L, Schubert K, Tufaro F: Sequential isolation of proteoglycan synthesis mutants by using herpes simplex virus as a selective agent: evidence for a proteoglycan-independent virus entry pathway. J Virol 1995, 69(6):3290-3298.

75. Bender FC, Whitbeck JC, Lou H, Cohen GH, Eisenberg RJ: Herpes simplex virus glycoprotein B binds to cell surfaces independently of heparan sulfate and blocks virus entry. J Virol 2005, 79(18):11588-11597.

76. Satoh T, Arii J, Suenaga T, Wang J, Kogure A, Uehori J, Arase N, Shiratori I, Tanaka S, Kawaguchi Y, Spear PG, Lanier LL, Arase H: PILRalpha is a herpes simplex virus-1 entry coreceptor that associates with glycoprotein B. Cell 2008, 132(6):935-944.

77. Arii J, Uema M, Morimoto T, Sagara H, Akashi H, Ono E, Arase H, Kawaguchi $Y$ : Entry of herpes simplex virus 1 and other alphaherpesviruses via the paired immunoglobulin-like type 2 receptor alpha. J Virol 2009, 83(9):4520-4527

78. Wang J, Fan Q, Satoh T, Arii J, Lanier LL, Spear PG, Kawaguchi Y, Arase H: Binding of herpes simplex virus glycoprotein $B(g B)$ to paired immunoglobulin-like type 2 receptor alpha depends on specific sialylated O-linked glycans on gB. J Virol 2009, 83(24):13042-13045.

79. Suenaga T, Satoh T, Somboonthum P, Kawaguchi Y, Mori Y, Arase H: Myelin-associated glycoprotein mediates membrane fusion and entry of neurotropic herpesviruses. Proc Natl Acad Sci USA 2010, 107(2):866-871.

80. Cao Z, Gao Y, Deng K, Williams G, Doherty P, Walsh FS: Receptors for myelin inhibitors: Structures and therapeutic opportunities. Mol Cell Neurosci 2010, 43(1):1-14.

81. Vicente-Manzanares M, Ma X, Adelstein RS, Horwitz AR: Non-muscle myosin II takes centre stage in cell adhesion and migration. Nat Rev Mol Cell Biol 2009, 10(11):778-790.

82. Arii J, Goto H, Suenaga T, Oyama M, Kozuka-Hata H, Imai T, Minowa A, Akashi $H$, Arase H, Kawaoka $Y$, Kawaguchi Y: Non-muscle myosin IIA is a functional entry receptor for herpes simplex virus-1. Nature 2010, 467(7317):859-862

83. Clement C, Tiwari V, Scanlan PM, Valyi-Nagy T, Yue BY, Shukla D: A novel role for phagocytosis-like uptake in herpes simplex virus entry. J Cell Biol 2006, 174(7):1009-1021.

84. Oh MJ, Akhtar J, Desai P, Shukla D: A role for heparan sulfate in viral surfing. Biochem Biophys Res Commun 2010, 391(1):176-181.

85. Bender FC, Whitbeck JC, Ponce de Leon M, Lou H, Eisenberg RJ, Cohen GH: Specific association of glycoprotein B with lipid rafts during herpes simplex virus entry. J Virol 2003, 77(17):9542-9552.

86. Scanlan PM, Tiwari V, Bommireddy S, Shukla D: Cellular expression of $\mathrm{gH}$ confers resistance to herpes simplex virus type-1 entry. Virology 2003, 312(1):14-24.

87. Parry C, Bell S, Minson T, Browne $\mathrm{H}$ : Herpes simplex virus type 1 glycoprotein H binds to alphavbeta3 integrins. J Gen Virol 2005, 86(Pt 1):7-10.

88. Galdiero M, Whiteley A, Bruun B, Bell S, Minson T, Browne H: Site-directed and linker insertion mutagenesis of herpes simplex virus type 1 glycoprotein H. J Virol 1997, 71(3):2163-2170.

89. Gianni T, Cerretani A, Dubois R, Salvioli S, Blystone SS, Rey F, CampadelliFiume G: Herpes simplex virus glycoproteins $\mathrm{H} / \mathrm{L}$ bind to cells independently of \{alpha\} $\{$ beta\} 3 integrin and inhibit virus entry, and their constitutive expression restricts infection. J Virol 2010, 84(8):4013-4025
90. Perez A, Li QX, Perez-Romero P, Delassus G, Lopez SR, Sutter S, McLaren N Fuller AO: A new class of receptor for herpes simplex virus has heptad repeat motifs that are common to membrane fusion proteins. J Virol 2005, 79(12):7419-7430.

91. Cheshenko N, Trepanier JB, Segarra TJ, Fuller AO, Herold BC: HSV usurps eukaryotic initiation factor 3 subunit $\mathrm{M}$ for viral protein translation: novel prevention target. PLoS One 2010, 5(7):e11829.

92. Copeland R, Balasubramaniam A, Tiwari V, Zhang F, Bridges A, Linhardt RJ, Shukla D, Liu J: Using a 3-O-sulfated heparin octasaccharide to inhibit the entry of herpes simplex virus type 1. Biochemistry 2008, 47(21):5774-5783.

93. Tiwari V, Liu J, Valyi-Nagy T, Shukla D: Anti-heparan sulfate peptides that block herpes simplex virus infection in vivo. J Biol Chem 2011, 286(28):25406-25415

94. Wittels M, Spear PG: Penetration of cells by herpes simplex virus does not require a low pH-dependent endocytic pathway. Virus Res 1991, 18(23):271-290.

95. Dollery SJ, Delboy MG, Nicola AV: Low pH-induced conformational change in herpes simplex virus glycoprotein B. J Virol 2010, 84(8):3759-3766

96. Tiwari V, Oh MJ, Kovacs M, Shukla SY, Valyi-Nagy T, Shukla D: Role for nectin-1 in herpes simplex virus 1 entry and spread in human retinal pigment epithelial cells. FEBS J 2008, 275(21):5272-5285.

97. Nicola AV, McEvoy AM, Straus SE: Roles for endocytosis and low pH in herpes simplex virus entry into HeLa and Chinese hamster ovary cells. J Virol 2003, 77(9):5324-5332.

98. Stiles KM, Milne RS, Cohen GH, Eisenberg RJ, Krummenacher C: The herpes simplex virus receptor nectin-1 is down-regulated after trans-interaction with glycoprotein D. Virology 2008, 373(1):98-111.

99. Delboy MG, Patterson JL, Hollander AM, Nicola AV: Nectin-2-mediated entry of a syncytial strain of herpes simplex virus via $\mathrm{pH}$-independent fusion with the plasma membrane of Chinese hamster ovary cells. Virol J 2006, 3:105.

100. Nicola AV, Straus SE: Cellular and viral requirements for rapid endocytic entry of herpes simplex virus. J Virol 2004, 78(14):7508-7517.

101. Gianni T, Gatta V, Campadelli-Fiume G: \{alpha\}V\{beta\}3-integrin routes herpes simplex virus to an entry pathway dependent on cholesterol-rich lipid rafts and dynamin2. Proc Natl Acad Sci USA 2010, 107(51):22260-22265

102. Linehan MM, Richman S, Krummenacher C, Eisenberg RJ, Cohen GH, Iwasaki A: In vivo role of nectin-1 in entry of herpes simplex virus type 1 (HSV-1) and HSV-2 through the vaginal mucosa. J Virol 2004, 78(5):2530-2536

103. Schlitt M, Lakeman AD, Wilson ER, To A, Acoff RW, Harsh GR, Whitley RJ: A rabbit model of focal herpes simplex encephalitis. J Infect Dis 1986, 153(4):732-735.

104. Bernstein DI, Ireland J, Bourne N: Pathogenesis of acyclovir-resistant herpes simplex type 2 isolates in animal models of genital herpes: models for antiviral evaluations. Antiviral Res 2000, 47(3):159-169.

105. Burgos JS, Ripoll-Gomez J, Alfaro JM, Sastre I, Valdivieso F: Zebrafish as a new model for herpes simplex virus type 1 infection. Zebrafish 2008, 5(4):323-333.

106. Sears AE, McGwire BS, Roizman B: Infection of polarized MDCK cells with herpes simplex virus 1: two asymmetrically distributed cell receptors interact with different viral proteins. Proc Natl Acad Sci USA 1991, 88(12):5087-5091.

107. Menotti L, Lopez M, Avitabile E, Stefan A, Cocchi F, Adelaide J, Lecoca E, Dubreuil P, Campadelli-Fiume G: The murine homolog of human Nectin1delta serves as a species nonspecific mediator for entry of human and animal alpha herpesviruses in a pathway independent of a detectable binding to gD. Proc Natl Acad Sci USA 2000, 97(9):4867-4872.

108. Shukla D, Rowe CL, Dong Y, Racaniello VR, Spear PG: The murine homolog (Mph) of human herpesvirus entry protein B (HveB) mediates entry of pseudorabies virus but not herpes simplex virus types 1 and 2. J Virol 1999, 73(5):4493-4497.

109. Shworak NW, Liu J, Fritze LM, Schwartz JJ, Zhang L, Logeart D, Rosenberg RD: Molecular cloning and expression of mouse and human CDNAs encoding heparan sulfate D-glucosaminyl 3-O-sulfotransferase. $J$ Biol Chem 1997, 272(44):28008-28019. 
110. Cadwallader AB, Yost HJ: Combinatorial expression patterns of heparan sulfate sulfotransferases in zebrafish: I. The 3-O-sulfotransferase family. Dev Dyn 2006, 235(12):3423-3431.

111. Hubbard S, Darmani NA, Thrush GR, Dey D, Burnham L, Thompson JM, Jones K, Tiwari V: Zebrafish-encoded 3-O-sulfotransferase-3 isoform mediates herpes simplex virus type 1 entry and spread. Zebrafish 2010, 7(2):181-187.

112. Wagner EK, Bloom DC: Experimental investigation of herpes simplex virus latency. Clin Microbiol Rev 1997, 10(3):419-443.

113. Grest $P$, Albicker P, Hoelzle L, Wild P, Pospischil A: Herpes simplex encephalitis in a domestic rabbit (Oryctolagus cuniculus). J Comp Pathol 2002, 126(4):308-311.

114. Weissenböck H, Hainfellner JA, Berger J, Kasper I, Budka H: Naturally occurring herpes simplex encephalitis in a domestic rabbit (Oryctolagus cuniculus). Vet Pathol 1997, 34(1):44-47.

115. Liu T, Khanna KM, Carriere BN, Hendricks RL: Gamma interferon can prevent herpes simplex virus type 1 reactivation from latency in sensory neurons. J Virol 2001, 75(22):11178-11184.

116. Knickelbein JE, Khanna KM, Yee MB, Baty CJ, Kinchington PR, Hendricks RL: Noncytotoxic lytic granule-mediated CD8+ T cell inhibition of HSV-1 reactivation from neuronal latency. Science 2008, 322(5899):268-271.

117. Kopp SJ, Banisadr G, Glajch K, Maurer UE, Grünewald K, Miller RJ, Osten P, Spear PG: Infection of neurons and encephalitis after intracranial inoculation of herpes simplex virus requires the entry receptor nectin-1. Proc Natl Acad Sci USA 2009, 106(42):17916-17920.

118. Renis HE, Eidson EE, Mathews J, Gray JE: Pathogenesis of herpes simplex virus types 1 and 2 in mice after various routes of inoculation. Infect Immun 1976, 14(2):571-578

119. Sekizawa T, Openshaw H: Encephalitis resulting from reactivation of latent herpes simplex virus in mice. J Virol 1984, 50(1):263-266.

120. Gebhardt BM, Halford WP: Evidence that spontaneous reactivation of herpes virus does not occur in mice. Virol J 2005, 2:67.

121. Dasgupta G, Benmohamed L: Of mice and not humans: How reliable are animal models for evaluation of herpes CD8(+)-T cell-epitopes-based immunotherapeutic vaccine candidates? Vaccine 2011, 29(35):5824-5836.

122. Chentoufi AA, Dasgupta G, Christensen ND, Hu J, Choudhury ZS, Azeem A, Jester JV, Nesburn AB, Wechsler SL, BenMohamed L: A novel HLA (HLA$\left.A^{*} 0201\right)$ transgenic rabbit model for preclinical evaluation of human CD8+ T cell epitope-based vaccines against ocular herpes. J Immunol 2010, 184(5):2561-2571.

123. Tiwari V, Shukla SY, Yue BY, Shukla D: Herpes simplex virus type 2 entry into cultured human corneal fibroblasts is mediated by herpesvirus entry mediator. J Gen Virol 2007, 88(Pt 8):2106-2110.

124. Akhtar J, Tiwari V, Oh MJ, Kovacs M, Jani A, Kovacs SK, Valyi-Nagy T, Shukla D: HVEM and nectin-1 are the major mediators of herpes simplex virus 1 (HSV-1) entry into human conjunctival epithelium. Invest Ophthalmol Vis Sci 2008, 49(9):4026-4035.

125. Shah A, Farooq AV, Tiwari V, Kim MJ, Shukla D: HSV-1 infection of human corneal epithelial cells: receptor-mediated entry and trends of reinfection. Mol Vis 2010, 16:2476-2486.

126. Shukla SY, Singh YK, Shukla D: Role of nectin-1, HVEM, and PILR-alpha in HSV-2 entry into human retinal pigment epithelial cells. Invest Ophthalmol Vis Sci 2009, 50(6):2878-2887.

127. Prandovszky E, Horváth S, Gellért L, Kovács SK, Janka Z, Toldi J, Shukla D, Vályi-Nagy T: Nectin-1 (HveC) is expressed at high levels in neural subtypes that regulate radial migration of cortical and cerebellar neurons of the developing human and murine brain. J Neurovirol 2008, 14(2):164-172.

128. Guzman G, Oh S, Shukla D, Engelhard HH, Valyi-Nagy T: Expression of entry receptor nectin-1 of herpes simplex virus 1 and/or herpes simplex virus 2 in normal and neoplastic human nervous system tissues. Acta Virol 2006, 50(1):59-66.

129. Choudhary S, Marquez M, Alencastro F, Spors F, Zhao Y, Tiwari V: Herpes Simplex Virus Type-1 (HSV-1) Entry into Human Mesenchymal Stem Cells Is Heavily Dependent on Heparan Sulfate. J Biomed Biotechnol 2011, 2011:264350.

doi:10.1186/1743-422X-8-48

Cite this article as: Karasneh and Shukla: Herpes simplex virus infects most cell types in vitro: clues to its success. Virology Journal 2011 8:481.

\section{Submit your next manuscript to BioMed Central and take full advantage of:}

- Convenient online submission

- Thorough peer review

- No space constraints or color figure charges

- Immediate publication on acceptance

- Inclusion in PubMed, CAS, Scopus and Google Scholar

- Research which is freely available for redistribution 